\title{
Responses to Comments of Weis
}

\author{
Na Guo ${ }^{1}$, Carlo A Marra ${ }^{1,2^{*}}$, Fawziah Marra ${ }^{3}$
}

\begin{abstract}
A response to Weis and Pasipanodya 'Measuring health-related quality of life in tuberculosis: a systemic review Response'.
\end{abstract}

\section{Letter to the Editor}

We thank Weis and Pasipanodya for their valuable and insightful comments on our published manuscript, Measuring health-related quality of life in tuberculosis: a systemic review [1]. However, we want to address their question regarding our statement "A validated tuberculosis-specific quality of life instrument was not located". When we searched for a "validated tuberculosis-specific quality of life instrument" for our literature review, there were two requirements that we had determined apriori. Firstly, the quality of life (QoL) instrument had to be originally designed and tailored specifically to assess a tuberculosis (TB) population; and secondly, the involved QoL instrument had to be validated in various TB populations.

Subjective measurements, such as QoL, are always prone to inherent biases. Validation is an important process involving the accumulation of evidences to provide a sound scientific basis to support the inferences of their psychometric properties. In addition, the quality of validation evidences is very important. Although there is no rule of thumb when validating a QoL instrument, a number of considerations should be taken into account - for example reliability, validity and responsiveness, representative samples of the targeted population, appropriate analysis techniques, and controls over plausible confounding factors [2].

Through our literature review, we only found one QoL instrument, the DR-12 [3], which was designed specifically for use in TB infected populations. However, as we stated in our manuscript [1], it has only been used once in a sample of active TB patients and the validation was not done in a systematic fashion. More

\footnotetext{
* Correspondence: Carlo.marra@ubc.ca

${ }^{1}$ Collaboration for Outcomes Research and Evaluation (CORE), Faculty of Pharmaceutical Sciences, University of British Columbia, Vancouver, BC, Canada
}

applications with better validation methods are needed to further establish the psychometric properties of the DR-12.

Finally, we agree with Weis and Pasipanodya that item banking is a promising direction for QoL measurements. Item banking is a large collection of items that are measuring the same health construct and calibrated onto common scales using item response theory (IRT) based approaches. A new generation of health outcomes measurements, computerized adaptive testing (CAT), which combines modern measurement theory, IRT, with advanced computer technologies, has the potential to optimize measurement precision [4-8].

\section{Author details \\ ${ }^{1}$ Collaboration for Outcomes Research and Evaluation (CORE), Faculty of Pharmaceutical Sciences, University of British Columbia, Vancouver, BC, Canada. ${ }^{2}$ Centre for Health Evaluation and Outcome Sciences (CHEOS), Providence Health Care Research Institute, Vancouver, BC, Canada. ${ }^{3}$ Faculty of Pharmaceutical Sciences, University of British Columbia, Vaccine and Pharmacy Services, British Columbia Centre for Disease Control (BCCDC), Vancouver, BC, Canada.}

Received: 2 December 2009

Accepted: 15 January 2010 Published: 15 January 2010

\section{References}

1. Guo N, Marra F, Marra C: Measuring health-related quality of life in tuberculosis: a systematic review. Health Qual Life Outcomes 2009, 7:14

2. Streiner DL, Norman GR: Health measurement scales: A Practical Guide to Their Development and Use. Oxford Medical Publications, 31995.

3. Dhingra VK, Rajpal S: Health related quality of life (HRQL) scoring in tuberculosis. India J Tuberc 2003, 50:99-104.

4. Bjorner JB, Kosinski M, Ware JE Jr: Calibration of an item pool for assessing the burden of headaches: an application of item response theory to the headache impact test (HIT). Qual Life Res 2003, 12:913-933.

5. Fliege $H$, Becker J, Walter OB, Bjorner JB, Klapp BF, Rose M: Development of a computer-adaptive test for depression (D-CAT). Qual Life Res 2005, 14:2277-2291.

6. Lai JS, Cella D, Dineen $K$, et al: An item bank was created to improve the measurement of cancer-related fatigue. J Clin Epidemiol 2005, 58:190-197.

7. Lai JS, Cella D, Dineen K, Bode R, Von Roenn J, Gershon RC, Shevrin D: Assessment of health-related quality of life in arthritis: conceptualization
C Biomed Central

C 2010 Guo et al; licensee BioMed Central Ltd. This is an Open Access article distributed under the terms of the Creative Commons Attribution License (http://creativecommons.org/licenses/by/2.0), which permits unrestricted use, distribution, and reproduction in any medium, provided the original work is properly cited. 
and development of five item banks using item response theory. Health Qual Life Outcomes 2006, 4:33.

8. Walter OB, Becker J, Bjorner JB, Fliege H, Klapp BF, Rose M: Development and evaluation of a computer adaptive test for 'Anxiety' (Anxiety-CAT). Qual Life Res 2007, 16(Suppl 1):143-155.

doi:10.1186/1477-7525-8-6

Cite this article as: Guo et al:: Responses to Comments of Weis. Health and Quality of Life Outcomes 2010 8:6.

Publish with BioMed Central and every scientist can read your work free of charge

"BioMed Central will be the most significant development for disseminating the results of biomedical research in our lifetime. " Sir Paul Nurse, Cancer Research UK

Your research papers will be:

- available free of charge to the entire biomedical community

- peer reviewed and published immediately upon acceptance

- cited in PubMed and archived on PubMed Central

- yours - you keep the copyright 